\title{
Communicating knowledge about police performance
}

\author{
Paul M. Collier \\ John S. Edwards \\ Duncan Shaw
}

Aston Business School, Aston University

Paul Collier is Senior Lecturer in Management Accounting, John Edwards is

Professor of Operations Research and Systems, and Duncan Shaw is Lecturer in Strategic Decision Making, all at Aston Business School, Birmingham UK

Corresponding Author:

Dr Paul Collier, Aston Business School, Aston University, Birmingham B4 7ET U.K.

Tel + 44 (0) 1213593011 ext. 5082

Email p.m.collier@aston.ac.uk 


\section{Communicating knowledge about police performance}

\section{$\underline{\text { ABSTRACT }}$}

This paper describes the organizational processes of knowledge acquisition, sharing, retention and utilisation as it affected the internal and external communication of knowledge about performance in an English police force.

The research was gathered in three workshops: one for internal personnel, one for external stakeholders and one for chief officers using Journey Making, a computerassisted method of developing the shared understanding of a group about an issue.

The research concluded that there are multiple audiences for the communication of knowledge about police performance, impeded by the requirement to publish performance data in set ways. However, the development of the intelligence-led policing model has the possibility of leading to a more focused means of communication with various stakeholder groups.

Although technology investment was a preferred means of communicating knowledge about performance, without addressing cultural barriers, an investment in technology may not yield the appropriate changes in behaviour. Consequently, technology needs to be integrated with working practices in order to reduce organizational reliance on informal methods of communication.

\section{KEYWORDS}

Knowledge management, performance management, policing, communications strategy, stakeholders 


\section{Communicating knowledge about police performance}

\section{$\underline{\text { INTRODUCTION }}$}

Knowledge management is a crucial element of policing which is subject to a wide variety of laws and regulations governing crime, evidence, legal precedent and rules of police behaviour which needs to be shared. At the same time, police forces are increasingly accountable to government at various levels and to the community at large for various aspects of their performance and are expected to communicate with government and the public about what they are doing.

In the UK, a tripartite system of governance at both the national and local level together with financing from both sources leads to the serious consideration by police forces of how best to communicate knowledge about performance to the public and to their own personnel. This paper describes a study in which the research focus was on the organizational processes of knowledge acquisition, sharing, retention and utilisation as it affected the internal and external communication of knowledge about performance in an English police force.

In the first section, the paper introduces the framework of knowledge management including the limited police research on this subject and the background of policing in the UK. In the second section the methodology is described. The third section describes the research data. The fourth section discusses the implications for police forces and presents some conclusions. 


\section{KNOWLEDGE MANAGEMENT AND POLICING}

$\underline{\text { Research into knowledge management }}$

In their study of the Singapore Police Force, Luen \& Al-Hawamdeh (2001) found that the vast knowledge that police officers need in order to perform their normal duties required them to be proficient knowledge workers, being able to access, assimilate and use knowledge effectively to discharge their duties. Building on the distinction made by Nonaka (1991) between explicit and tacit knowledge, Luen \& Al-Hawamdeh argued that managing explicit knowledge involved a framework comprising identification of appropriate knowledge; capturing and documenting knowledge that has been identified; the systematic organization of captured knowledge; storage of knowledge that allows easy access; retrieval to meet user needs; and reviewing knowledge to keep it up to date. Tacit knowledge involved both the ability and willingness to create and share knowledge, requiring an organizational culture that recognized and valued knowledge and knowledge sharing.

In his UK study, Collier (2001) identified five mechanisms for acquiring and maintaining knowledge in police forces (although he referred to this as the intellectual capital of police forces): formal training and on-the-job experience; knowledge sharing through briefing and debriefing; knowledge structures including paper-based manuals and computer databases; hierarchical redundancy through the command structure which supports the cascading of knowledge; and amortization through the loss of skills due to promotion, retirement or tenure policies and through legislative, policy and technological change. 
Practitioner and academic interest in knowledge management has grown at least in part out of the organizational learning literature, reviews of which have been carried out by Huber (1991); Dodgson (1993); Nicolini \& Meznar (1995) and Easterby-Smith (1997). Definitions of organizational learning have one shared feature: they see the environment as a stimulus for learning.

A major concern of the organizational learning literature has been with individual learning within organizations (for example Stata (1989) and Senge (1990)) although there has also been an information systems perspective that has emphasized organizational memory as a form of systems architecture. However, the broader literature on knowledge management has brought together social aspects of learning with more technological views of knowledge management (Vince, Sutcliffe, \& Olivera (2002)).

Wiig (1997) defined knowledge management as the effective management of knowledge processes, the purpose of which is to maximise organizational knowledgerelated effectiveness and the returns from knowledge assets and to constantly renew those assets.

Knowledge management has been described as the process of creating, capturing and using knowledge to enhance organizational performance (Davenport \& Prusak (1998); Bassi (1998); Parlby (1997)). There are many published descriptions of the processes and activities of knowledge management, although no one has gained common acceptance (for a detailed summary see Beckman (1999)). 


\section{$\underline{\text { Policing in England and Wales }}$}

Policing in England and Wales is governed by the Police Act of 1996 which prescribes a tripartite structure, comprising the Home Secretary at the national level and a police authority and chief constable for each of the 43 police forces in England and Wales (the police forces in Scotland and Northern Ireland are covered by different legislation).

The Chief Constable is the professional head of the police force, with responsibility for the 'direction and control' of the force. Operational police work is carried out by commanders of Basic Command Units (BCUs) within each force. These are geographical units covering several police stations, with most BCUs coterminous with local authority boundaries. BCUs are supported by a number of Headquarters-based departments providing specialist policing functions and support services.

The Police Authority has responsibility to maintain an 'efficient and effective' force for its area. It comprises members from local authorities, independent members and representatives of Magistrates' Courts. Its role is to act on behalf of local people and, on the basis of local consultation and through community consultation, to set the budget and review objectives and performance targets in conjunction with the Chief Constable and to issue a policing plan for the Authority's area.

The Home Secretary has a duty to promote the efficiency of the Police Service nationally and carries out this power after consultation with the Association of Chief 
Police Officers (ACPO: representing chief officers of all police forces) and the Association of Police Authorities. Her Majesty's Inspector of Constabulary (HMIC) provides a source of professional advice to the Home Secretary on all aspects of policing. The government's expectations about police performance are most evident in the publication of performance indicators which results in comparative performance measures between police forces. These expectations are reinforced by inspections carried out by HMIC and by the work of the Police Standards Unit in the Home Office.

Police funding - along with expectations about police performance - is an outcome of the UK government's annual Spending Review and is allocated between forces on the basis of a formula which is both demographic and historical. However, police authorities are precepting bodies and can supplement their budget by increasing the police levy ${ }^{1}$ in the council tax. For most forces, national funding is inadequate to cover salary inflation, pension payments and capital investment. Consequently, most forces have found it necessary to increase the police levy in order to deliver the policing plan. A major issue over recent years has been the need for additional police officers and national funding has been specifically 'ring-fenced' to support a recruitment drive.

The force studied is an English police force with 2,400 police officers, 1,300 civilian staff and a budget of $£ 144$ million. Immediately prior to the research, the police authority had increased the police levy by $33 \%$ in order to recruit more police officers to support the force policing plan and meet the performance targets. The Chief 
Constable had decided to develop a communications strategy, to ensure that operational policing was delivered to justify the increase in the police levy and to put the policing plan into action. As part of the development of the communications strategy, the researchers were given access for the purposes of their research.

\section{$\underline{\text { METHODOLOGY }}$}

The research was conducted through three workshops, one each for internal staff, external stakeholder representatives and chief officers. The workshops were all held between April and June 2002 and the results were subsequently reported to the force. The internal and external workshops lasted a full day while the chief officer workshop was completed in a half day. There were 9 participants in the internal workshop, 11 in the external workshop and 5 in the chief officer workshop. The internal workshop included a BCU commander, an inspector and two police constables, together with the Director of Strategic Planning, the Head of Information Systems, and representatives of the department responsible for organization development.

The second workshop comprised external stakeholders. These comprised members of the police authority, a magistrate and member of the local race relations council, a local newspaper editor, a staff officer from HMIC, a representative of the Community Policing Panel and two business representatives. The third workshop comprised the Chief Constable, Deputy Chief Constable, one of two Assistant Chief Constables, the Director of Finance and the Director of Strategic Planning.

\footnotetext{
${ }^{1}$ A separately charged item in the local tax for each council area, over which each Police Authority has
} 
The research questions were:

1. What is the knowledge about performance that needs to be communicated?

2. What are the processes that are currently used and that should be used to acquire, share, retain and utilise knowledge?

3. What metrics are currently used or should be used in relation to acquire, share, retain and utilise knowledge?

The methodology adopted for the research was an adapted form of JOURNEY

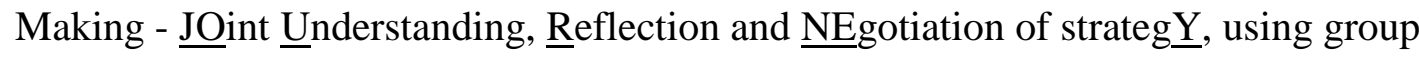
mapping (Eden \& Ackermann, 1998) as a means to capture participants' shared understanding and interpretation of the world in which they work.

Each participant had access to a laptop computer connected to a local area network. The advantage of the computer technology was that ideas generated by participants in response to research questions were only visible to the author until such time as the facilitator revealed all the participants' responses on a public screen. Group decision support software enabled the workshop facilitator to capture the data on a master laptop which was linked to a projector screen. Once participants had entered their ideas the facilitator allowed a public display of knowledge as the data on each laptop was projected onto a public screen. Participants could then enter additional ideas, using those of others as a prompt for their own ideas. The facilitator then led the process of clustering ideas around common themes. The themes were those that were meaningful to the participants.

total control. 
The technique used to share knowledge might be thought of as being similar to that of brainstorming, but is a development of that technique as group members are assisted in thinking freely about a problem. Allowing the respondents to synthesise their different views in a workshop helps in building a shared understanding of the issue and develops a more creative environment than participants sitting alone answering questions. Our belief was that it was crucial to study the understanding and beliefs of each group about the research, rather than the views of individuals.

The role of the researchers was two-fold. One researcher acted as facilitator to ensure the validity of the process and to ensure that participants' ideas were captured by the software. The other researchers took notes of the process and noted some of the 'aside' comments of participants. Subsequent to the three workshops, the researchers analysed the results by identifying common themes and aggregating workshop responses across those themes.

\section{RESEARCH DATA}

What knowledge needs to be communicated?

In our research, we defined data as raw facts. Information results from the processing of data for a purpose but without any interpretation (e.g. its summarisation and reporting). Knowledge implies the application of a cognitive process to the information so that it becomes useful. The police force studied used the concept of intelligence to describe what the researchers had called knowledge, emphasising its usability, particularly in relation to the force's intelligence-led policing strategy. The Deputy Chief Constable summarised this as "What? So what? Now what?" referring 
to the conversion of data (what?) into intelligence (so what?) and then into action (now what?).

We defined acquiring knowledge as gaining knowledge that the organization did not previously have. Sharing knowledge was concerned with exchanges of knowledge within the organization. Retaining knowledge was concerned with preventing its loss through attrition or decay. Utilising knowledge assumed that it was somehow connected with organizational performance.

In the internal workshop, knowledge about performance was largely related to the inputs to policing. The main clusters of knowledge were external changes (political, regulatory and press); frontline policing (driven by the force policing plan and national policing targets) and strategy (driven by the external cluster). Three organizational enablers were also identified: financial information, training, and partnerships with other agencies.

For the external workshop, the focus of knowledge was knowledge processes.

Clusters of knowledge were around historical crime statistics; local/current incidents; plans and policies; activity information about what officers were doing; environmental influences; financial information, especially initiatives with significant budgetary impacts; and how police services were improving as a result of the extra police officers being recruited.

One of the problems in the external stakeholder workshop was the diverse interests of the stakeholders and their different expectations. 86 different stakeholder groups 
were identified (which the group admitted was not exhaustive), clustered around 'communities' of stakeholders encompassing different demographic and socioeconomic groups, special interest groups, the business community, offenders, victims, the vulnerable, the establishment, education, etc. However, it was recognised that individuals could be members of multiple communities.

Interestingly, when each participant was asked to identify the knowledge they needed, not as a stakeholder representative but as a member of the public, the answers to this question were markedly different to the answers the participants had given in their role of stakeholder representatives. The common theme identified by participants was "What am I getting for the increase in my [council tax] bill?"

The chief officer orientation was around performance outputs. The knowledge clusters were financial (budgets and resources); performance (at force and BCU level); community (key events, stakeholder activities, community concerns, pressure group agendas); internal environment (the impact of plans and staff association agendas); operational (offenders, national issues, volume of activity); internal direction of the force (strategies and chief officer responsibilities); mandatory (legislation and ministerial requirements); and guidance (from the police authority, ACPO and Home Office).

\section{Processes for managing knowledge}

The internal workshop participants ranked the processes that would be most effective for communication. Verbal and informal communications dominated current 
processes and participants in the internal workshop wanted these reduced in favour of more formal electronic or written processes. The intranet was ranked as most effective for corporate communications, followed by publications, IT systems, meetings and email. The most effective processes for operational purposes were intelligence-led policing (informants, pattern analysis and tasking, etc.) followed by corporate information technology (IT) systems, radio, intranet and verbal methods. However, the participants agreed that "if you only put the information in one place that is where people will go to use it" and proposed that most knowledge be held on the intranet, a 'push' form of communication.

There were various suggestions about how this could be made to happen, particularly given the existence of what the BCU Commander called "recalcitrant noncommunicators". Considerable discussion took place around motivating reluctant people to 'pull' the required knowledge, reflecting the cultural barrier that existed. Some participants believed that it was the line managers' job to ensure their staff used the system. However, others considered that computer literacy was a barrier to the use of IT systems.

For the external workshop the variety of communications media suggested by participants reflected the nature of the different stakeholder groups, from newsletters and emails addressed to the business community to meetings, newspapers, surgeries, posters, websites, face-to-face, personal letters and telephone. One participant commented that "Lots of this is already done but it isn't focussed." 
In the chief officer workshop, the Chief Constable referred to this as "Getting people to listen, understand and do something. It's about intellectual engagement." A wide variety of ideas resulted, including a communications strategy, using specialists, reinforcing culture by "walking the talk", giving briefings at various levels, and linking to the performance appraisal process. However, most ideas emphasised "keeping it simple".

\section{$\underline{\text { Metrics for knowledge management }}$}

The internal workshop concentrated on how the effectiveness of the intranet could be evaluated. The participants contributed a number of ideas for quantitative and qualitative aspects of evaluation, and again there were a number of clusters. Input measures were reflected in the number of log-ons and hits, while content and quality was measured by user satisfaction and complaints. Functionality was measured by speed and ease of use and output was through knowledge checks. The outcomes that could be achieved were largely less time spent on briefings, and the achievement of the force strategy as evidenced by performance improvement.

The responses from the external workshop identified measures of the methods used for two-way communication with external stakeholders, such as surveys, focus groups, crime statistics and the rate of detection, media reports, follow-up calls, and feedback, although the external workshop participants recognised that different measures were applicable to different stakeholder groups. One of the problems identified was managing community expectations. The example of false alarms was an important one to business representatives, who wanted more police attention. By 
contrast, the police authority, in the knowledge that $98 \%$ of alarm responses were false alarms wanted to reduce the resources allocated. The community view was that listening to an unanswered alarm for eight hours was not acceptable.

The chief officer workshop identified three broad clusters for measuring the effectiveness of the communication of knowledge, although the difficulty of measurement was recognised. For internal management, comments included "everyone knows what they should be doing", "the intranet is used by staff", "organisational terrorists have less scope to operate", "no duplication of effort", and "procedures are followed easier/naturally".

For policing in partnership with the community, the measures were "hard to reach groups are in contact with us", "the community are aware of what we are doing", "local newspapers carry the message without being asked", and "public expectations become more realistic".

The third cluster was in relation to changes in behaviour (covering the public, police and offenders). Measures were "more people are willing to give evidence", "people drive slower even if there is not a camera in sight", "order is maintained in the community through self discipline rather than being imposed by us", "fewer people are arrested and cautioned" and "the amount of drugs available and consumed goes down".

\section{Communications Strategy}


After the workshops, the force developed a communications strategy, using the results of the workshops to assist in that process. This was completed late in 2002 . The communications strategy highlighted the importance of changing processes, recognising that communication was a shared responsibility, particularly as the force relied on strong partnerships with other organizations. Many of the different audiences for communication were identified in the draft strategy, grouped into internal, external and media. A subsidiary group of "opinion formers" was also identified as a result of "their views having a wide reaching impact across the communities of [force name] and beyond" as well as a critical role in informing the force about the expectations of various community groups.

The strategy noted the tension between formal communications which were based on statutory requirements which "currently form the greatest part of our communications yet their impact on delivering policing and the [strategy] is minimal.” The force internet site was identified as a primary communication medium both for disseminating knowledge and capturing the opinions of the general public. The intranet was identified as the primary communications channel for internal communications. However, the communications strategy identified sufficient resources being made available as a critical success factor and reflected that to effectively disseminate knowledge about performance, the medium "needs to be the best method for the recipient, not the most convenient way for you to issue it!"

\section{$\underline{\text { IMPLICATIONS }}$}


The issues arising from the first research question were the sheer volume and variety of knowledge; the different expectations of multiple external stakeholder groups; the difficulty of communicating to the 'general public' through those stakeholder groups and the usability of knowledge as 'intelligence'. It was also clear that knowledge flow was not just from the police force to the community but that the police force also had expectations about knowledge it wanted from the community.

For the second research question it was generally agreed that the way forward was to develop the intranet operationally as well as corporately. Information technology was seen as the solution, as the general absence of formal processes placed greater reliance on individuals, leading to a dependence on informal systems. However, the communications strategy recognised that the adoption of this technology had significant resource implications.

In the external workshop, it was apparent that multiple information systems and control devices would be necessary to provide the knowledge asked for by so many different stakeholder groups. The volume of data requested also raised questions about the multiple accountabilities of the police to different stakeholders and the amount of resources that were allocated to satisfying the disparate needs of multiple communities of stakeholders. An important issue from the external workshop was that while much knowledge flowed to a variety of stakeholder groups, that knowledge did not cascade down to the general public - indeed, there was no single group that could be identified as the general public. 
The third research question identified the push and pull considerations to encourage greater use of knowledge that was held - or should be held - on the intranet. The external workshop participants recognised that a central problem was managing community expectations. For chief officers, a major consideration was that knowledge needed to change the behaviour of the public, the police and offenders.

In the internal workshop, knowledge about performance was largely related to the inputs to policing. For the external workshop, the focus of knowledge was knowledge processes. As individuals, the common theme identified by participants was "What am I getting for the increase in my [council tax] bill?" The chief officer orientation was around performance outputs.

In the internal workshop, the preferred process for sharing knowledge was the intranet The external workshop preferred more personal communications including letters and meetings. Chief officers wanted intellectual engagement while keeping messages simple. A variety of measures of the effectiveness of communication processes were offered, which mirrored the workshop preferences about processes for sharing knowledge.

The different focuses of each workshop demonstrated the crucial role of chief officers in managing both internal and external expectations. The three police workshops exemplified the vast quantities of knowledge, the large numbers of interested stakeholders and the necessity for the top management team to balance competing priorities. In operational terms, the focus was on using an intelligence-led style of policing to achieve the strategy contained in the policing plan. In management terms, 
this was largely about balancing competing demands for resources and achieving a cultural shift through converting raw data into useful intelligence and subsequently into action.

The theme of converting data into intelligence and into action was an important one which involved chief officers focusing more on what is really important and having communication systems to support this, although it was recognised that this involved significant cultural shifts by chief officers themselves who as individuals tried to absorb vast quantities of knowledge.

Chief officers are in the centre of the communication of knowledge in both internal and external environments and see the policing plan and performance targets as the link between those environments. However, it was evident that the knowledge expected by stakeholders, whether in relation to their interest groups or as members of the public, was quite different to the knowledge about performance reported publicly. It seems therefore that regulatory requirements, particularly targets and priorities dictated by central government may not represent the most effective means by which communication with the public is best carried out even though such publication is intended to make forces more accountable.

\section{CONCLUSIONS}

The main findings of the research are that there are multiple audiences for the communication of knowledge about police performance - both inside and outside a police force. Communication is a two-way process with chief officers needing to 
balance government demands with the expectations of local stakeholder groups and to communicate their strategy clearly both internally and externally.

Our research concluded that, for this police force, effective knowledge management needs to combine individual learning with a technology base. In the present study, it was clear that there were cultural barriers to communicating knowledge, supporting the work of Luen \& Al-Hawamdeh (2001) referred to earlier in this paper. Without addressing the cultural barriers, an investment in technology may not yield the appropriate changes in behaviour. To achieve this, technology needs to be integrated with working practices in order to reduce organizational reliance on informal methods of communication.

Finally, the need to communicate effectively with multiple stakeholder groups is likely to be impeded by the requirement to publish performance data in set ways. The tension between the demands of central government and the expectations of the local community for accountability can only be addressed at a national level by the Home Office, Association of Chief Police Officers and Association of Police Authorities working together.

A major focus for chief police officers is to find ways to manage external expectations about performance while changing the behaviour of the public, police officers and offenders. We found that the development of the intelligence-led policing model presents an opportunity for police forces to deliver a more targeted and focused means of communication to the various stakeholder groups. 


\section{$\underline{\text { REFERENCES }}$}

Bassi, L. (1998). Harnessing the power of intellectual capital. Journal of Applied Manufacturing Systems(Summer), 29-35.

Beckman, T. J. (1999). The current state of knowledge management. In J. Liebowitz (Ed.), Knowledge Management Handbook. Boca Raton: CRC Press.

Collier, P. M. (2001). Valuing intellectual capacity in the police. Accounting, Auditing \& Accountability Journal, 14(4), 437-55.

Davenport, T. H., \& Prusak, L. (1998). Working knowledge: how organizations manage what they know. Boston, Mass.: Harvard Business School Press.

Dodgson, M. (1993). Organizational learning: A review of some literatures. Organization Studies, 14(3) 375-91.

Easterby-Smith, M. (1997). Disciplines of organizational learning: Contributions and Critiques. Human Relations, 50(9), 1085-1113.

Eden, C., \& Ackermann, F. (1998). Making Strategy: The Journey of Strategic Management. London: Sage.

Huber, P. (1991). Organizational Learning: The Contributing Processes and the Literatures. In M. D. Cohen \& L. S. Sproull (Eds.), Organizational Learning Thousand Oaks, Ca.: Sage Publications.

Luen, T. W., \& Al-Hawamdeh, S. (2001). Knowledge management in the public sector: principles and practices in police work. Journal of Information Science, 27(5), 311-18.

Nicolini, D., \& Meznar, M. B. (1995). The social construction of organizational learning: Conceptual and practical issues in the field. Human Relations, 48(7). 
Nonaka, I. (1991). The Knowledge-Creating Company. Harvard Business Review, Nov-Dec, 96-104.

Parlby, D. (1997). The Power of Knowledge: A business guide to knowledge management. KPMG Management Consulting.

Senge, P. M. (1990). The Fifth Discipline: The Art and Practice of the Learning Organization London: Century Business.

Stata, R. (1989). Organizational Learning - The Key to Management Innovation. Sloan Management Review, Spring, 63-74.

Vince, R., Sutcliffe, K., \& Olivera, F. (2002). Organizational Learning: New Directions. British Journal of Management, 13(Special Issue), S1-S6.

Wiig, K. M. (1997). Knowledge Management: An Introduction and Perspective. Journal of Knowledge Management, 1(1), 6-14. 